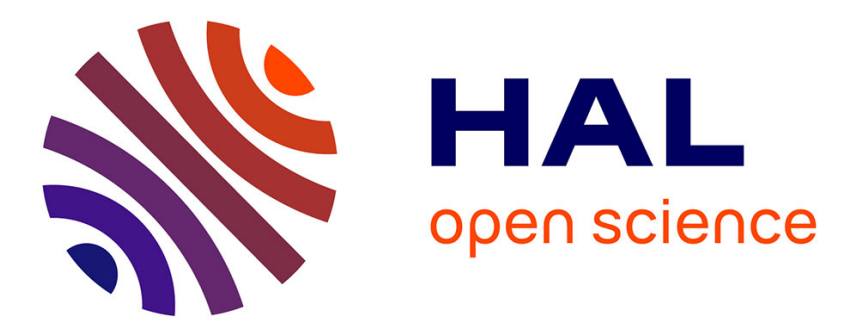

\title{
PHONON PULSE REFLECTION FROM FRESHLY CLEAVED INTERFACES BETWEEN SOLIDS AND LIQUID HELIUM
}

\author{
J. Weber, W. Sandmann, W. Dietsche, H. Kinder
}

\section{To cite this version:}

J. Weber, W. Sandmann, W. Dietsche, H. Kinder. PHONON PULSE REFLECTION FROM FRESHLY CLEAVED INTERFACES BETWEEN SOLIDS AND LIQUID HELIUM. Journal de Physique Colloques, 1978, 39 (C6), pp.C6-242-C6-243. 10.1051/jphyscol:19786106 . jpa-00217509

HAL Id: jpa-00217509

https://hal.science/jpa-00217509

Submitted on 1 Jan 1978

HAL is a multi-disciplinary open access archive for the deposit and dissemination of scientific research documents, whether they are published or not. The documents may come from teaching and research institutions in France or abroad, or from public or private research centers.
L'archive ouverte pluridisciplinaire HAL, est destinée au dépôt et à la diffusion de documents scientifiques de niveau recherche, publiés ou non, émanant des établissements d'enseignement et de recherche français ou étrangers, des laboratoires publics ou privés. 


\section{PHONON PULSE REFLECTION FROM FRESHLY CLEAVED INTERFACES BETWEEN SOLIDS AND LIQUID HELIUM}

J. Weber, W. Sandmann, W. Dietsche and H. Kinder,

Physyk-Department $E$ 10, Technische Universität Minchen, 8046 Garching, West-Germany.

Résumé.- Les impulsions de phonons à $290 \mathrm{GHz}$ ont été réfléchies des surfaces solides dans 1 'hélium liquide. Pour 1a première fois les surfaces ont été clivées (fraiches) à 1K. Il est surprenant d'observer des coefficients de réflection non loin de $100 \%$ pour ces surfaces presque idéales.

Abstract.- Phonon pulses of $290 \mathrm{GHz}$ were reflected from solid surfaces in contact with 1 iquid helium. The surfaces were freshly cleaved at $1 \mathrm{~K}$, for the first time. Surprisingly, the reflection coefficient was nearly $100 \%$ on these almost ideal surfaces.

In recent years, experiments with phonon pulses have yielded direct information on the energy transfer between solids and liquid helium (Kapitza conductance) $/ 1,2 /$. At high temperatures $(>1 \mathrm{~K})$ or high phonon frequencies, (>50 GHz) respectively, this energy transfer is roughly 100 times more effective than the Khalatnikov process /3/ of single phonon transmission with conservation of energy and momentum (acoustic mismatch model). The underlying microscopic process of this highly effective energy transfer is still not understood.

One basic question to be answered experimentally was that of the process being an intrinsic effect of ideal surfaces or whether it was caused by irregularities $/ 4 /$. We report here on experiments with nearly ideal surfaces which were prepared by cleaving in situ at $1 \mathrm{~K} / 5 /$.

The reflection of phonon pulses of $290 \mathrm{GHz}$ was measured using superconducting tunneling junctions /6/. The junctions were evaporated on one side of an LiF crystal, whose far side extended into a vacuum chamber (see inset of Fig. 1). The crystal could be cleaved by a razor blade which was moved by a screw. Through the thread of this screw, the chamber was connected to a filling line which was normally also kept at an ultra high vacuum.

The echo pulses before cleaving are shown by the dash-dotted line of figure 1. The first pulse is a pure transverse mode, with the direction of polarization parallel to the surface. The second pulse is an oblique mode with an angle of $20^{\circ}$ between the phase velocity and the normal or the surface. After cleaving, the time of flight was shor- ter, natura11y. The solid trace was still taken under UHV conditions (a vacuum of better $10^{-12}$ torr was estimated). The dotted trace was taken after helium was introduced into the chamber.

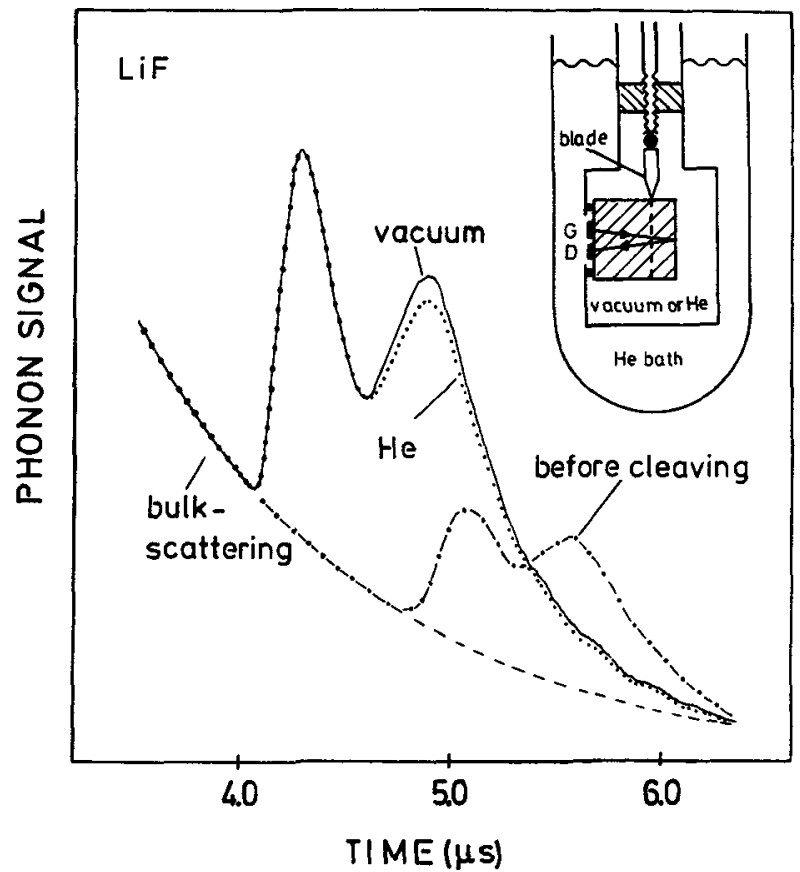

Fig. 1 : Phonon echo pulses vs.time; dash-dotted trace : before cleaving in vacuum; solid trace freshly cleaved surface in vacuum; dotted trace : same surface with bulk helium.

The first pulse, i.e. the purely transverse mode, was not changed at a11. This is in contrast to a11 previous experiments $/ 1 /$ where changes of the order of $50 \%$ were always observed, particularly for the transverse waves. On the other hand, the Khalatnikov 
model predicts exactly no energy transfer for pureIy transverse modes, indeed. This makes clear that the highly effective energy transfer ("anomalous" Kapitza conductance) is not intrinsic to ideal surfaces.

On the second pulse, i.e. the oblique mode, a change or $6 \%$ with helium is observed (see Fig.1) This change is smaller than on less ideal surfaces. For comparison, we have warmed the same crystal to room temperature and then exposed to air for one day. Thereafter, the solid trace of figure 2 was obtained in vacuum, and the dotted trace in helium. The helium effect was now $12 \%$ for the pure transverse mode, and $22 \%$ for the oblique mode. A still greater effect was obtained by wiping the surface with acetone or by mechanically polishing.

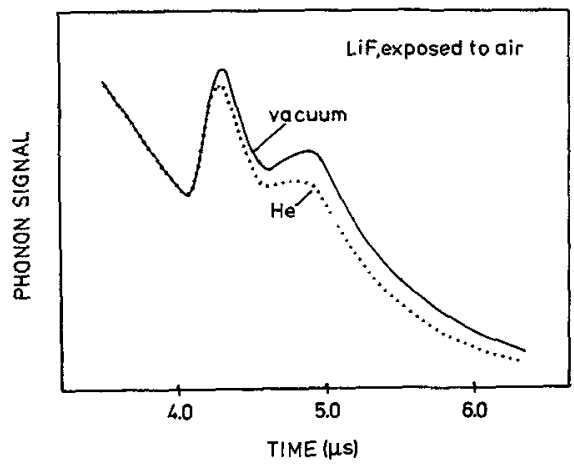

Fig. 2 : Cleaved surface of figure 1 after exposure to air at room temperature. Solid trace : vacuum; dotted trace : helium.

Therefore, it is natural to assume that the residual helium effect on the oblique mode of figure 1 was also caused by residual irregularities. Even on these atomically clean surface, which look smooth and shiny to the eye, there are steps and irregularities on an almost atomic scale which could be resolved by using an electron microscope. This view is supported by other experiments with less perfectly cleaved surfaces, when helium effects up to $10 \%$ were observed.

We conclude that the anomalously large energy transfer observed in phonon pulse and also in heat conductivity experiments is causes by surface irregularities rather than being an intrinsic effect of the ideal surface.

The fruitful discussions with $P$. Leiderer, J. Wolter and $V$. Narayanamurti are gratefully acknowledged.

\section{References}

/1/ Guo, C.J. and Maris, H.J., Phys. Rev. Lett. 29 (1972) 855

Kinder, H. and Dietsche, W., Phys. Rev. Lett. 33 (1974) 578

Long, A.R., Sherlock, R.A. and Wyatt, A.F.G., J. Low Temp. Phys. 15 (1974) 523 Dietsche, W. and Kinder, H., J. Low Temp. Phys. 23 (1976) 27

See also Sabisky, E.S. and Anderson, C.H., Solid State Commun 17 (1975) 1095

/2/ Swanenburg, T.J.B. and Wolter, J., Phys. Rev. Lett. 31 (1973) 693

Sherlock, R.A., Mills, N.G., Wyatt, A.F.G., J. Phys. C : Solid State Phys. $\underline{8}$ (1975) 300

/3/ Khalatnikov, I.M., Zh. Eksp. Teor. Fiz. 22 (1952) 687

/4/ Pollack, G.L., Rev. Mod. Phys. 41 (1969) 48

15/ Weber, J., Sandmann, W., Dietsche, W. and Kinder, H., submitted for publication

/6/ Kinder, H., Proceedings of the LT 14, Krusius, M. and Vuorio, M. eds., (North Holland/Elsevier) 1975, Vo1. 5, p. 287 